\title{
Genetic Diversity Analysis of Kabuli Chickpea (Cicer arietinum L.) Genotypes at Arsi-Robe, Southeastern Ethiopia
}

\author{
Gizachew Yilma Kebede*, Gebeyaw Achenef Haile \\ Ethiopian Institute of Agricultural Research (EIAR), Kulumsa Agricultural Research Center, Asella, Ethiopia
}

Email address:

gizachewy8@gmail.com (G. Y. Kebede), Gebesday08@gmail.com (G. A. Haile)

${ }^{*}$ Corresponding author

\section{To cite this article:}

Gizachew Yilma Kebede, Gebeyaw Achenef Haile. Genetic Diversity Analysis of Kabuli Chickpea (Cicer arietinum L.) Genotypes at ArsiRobe, Southeastern Ethiopia. Plant. Vol. 9, No. 3, 2021, pp. 58-65. doi: 10.11648/j.plant.20210903.13

Received: July 16, 2021; Accepted: July 27, 2021; Published: August 4, 2021

\begin{abstract}
Chickpea is an important pulse crop in Ethiopia; however, the production of the crop is not at its potential due to many constraints of which limited availability of high yielding varieties. Thus the main objectives of this study were to assess the magnitude of genetic diversity among kabuli chickpea genotypes for yield and yield related traits. Forty nine kabuli chickpea genotypes were evaluated for 11 traits in 2019/20 at Arsi Robe using 7 x 7 simple lattice designs with two replications. The analysis of variance result showed significant differences among genotypes. Cluster analysis showed the existence of wide variability among genotypes and grouped into six clusters. Maximum inter cluster distances were observed from cluster-IV and III followed by cluster IV and V, and cluster II and IV, while minimum inter cluster distances were found between cluster II and VI followed by cluster III and VI. The first three principal components explained about $66.1 \%$ of the total variations among the 49 kabuli chickpea genotypes. The first component accounts $34.58 \%$ of the total variation. It provides better opportunity for plant breeders to select parental materials to use for crossing in the breeding program. However, it requires multi-location and year trials to verify the consistency of existing genotypic variability.
\end{abstract}

Keywords: Cluster Analysis, Genetic Distance, Genetic Diversity, Inter Cluster Distance

\section{Introduction}

Chickpea (Cicer arietinum L.) belongs to the family leguminosae. It is one of the most important cool season food grain legumes in the world after common bean (Phaseolus vulgaris L.) and field pea (Pisum sativum L.) [1]. Chickpea is annual, self-pollinated and diploid species with $2 \mathrm{n}=2 \mathrm{x}=16$ chromosomes [2]. It is grown in 54 countries with nearly $90 \%$ of its area covered in developing countries [3]. Chickpea covered 242,703 ha, which is $15.2 \%$ of the pulse area, with 499,426 tons of grain production (16.8\% of pulses) [4]. Ethiopia is the largest producer, consumer and exporter of chickpea in Africa and shares about $4.5 \%$ of global and more than $60 \%$ of Africa's global chickpea market [5].

Two types of chickpea are known, namely kabuli and desi type. Kabuli type chickpea is one of the major pulses grown in Ethiopia, mainly grown under residual moisture which can also contribute for the low productivity and production. It has good sources of carbohydrate (54 to $71 \%$ ), protein (12.6 to $29 \%$ ), lipid (3.4 to $8.8 \%$ ), and energy (357 to $447 \mathrm{kcal} / 100 \mathrm{~g}$ ). Chickpea also contain fiber, minerals (calcium and phosphorus), vitamins and health beneficial phytochemicals and it is low in sodium, fat and cholesterol free [6]. Despite the significant economic importance of chickpea, the productivity remains low with national average yield of 2.05 $\mathrm{tha}^{-1}[4]$.

Increased the number of genotypes in plant genetic resource require tools for analyzing and classifying genetic variations for further utilization in crop breeding program. Genetic diversity among the parents is a prerequisite for the improvement and selecting better sergeant's materials for various traits. The more diverse parents have the more the chances of improving the characters under consideration. Cluster analysis refers to a multivariate statistical analysis technique used to partition a set of genotypes into groups 
based on the uniformity of traits they possess. Each cluster within a group is more similar among individual genotypes and more diverse from the individual in other cluster.

Chickpea is adapted to black soils in the cool semi-arid areas of the tropic, sub tropics as well as temperate areas. Arsi zone is one of the strategic areas for production of chickpea in Ethiopia. However, the production of the crop is constrained by many factors including the use of low productive farmers' varieties, together with unimproved traditional practices, biotic (Root rot, Ascochyta blight, Fusarium wilt, weed and pod borer) and abiotic (drought, soil salinity and water logging) factors [7].

The major problem of chickpea improvement program in Ethiopia has been lack of genotypes that consistently perform well across different chickpea growing environments and resistance to biotic factors. To improve those chickpea production problems, chickpea research was started before four decades in Ethiopia. Therefore, developing high yielding and disease resistant genotypes is very important for farmers to sustain their production and to ensure the sustainability of food and nutritional security in the target area. In view of this, the current research was conducted with the objectives of to assess the magnitude of genetic diversity among kabuli type chickpea genotypes for yield and yield related traits.

\section{Materials and Methods}

\subsection{Description of the Study Areas}

The experiment was conducted under field condition at Arsi-Robe research station during the 2019/20 main cropping season. Arsi-Robe is located at latitude of $07^{\circ} 53^{\prime} 02^{\prime \prime} \mathrm{N}$, longitude of $39^{\circ} 37^{\prime} 40^{\prime \prime} \mathrm{E}$ and an altitude of 2420 m.a.s.l. The average rainfall is $890 \mathrm{~mm}$ per annum having peaks in July and August. The mean maximum and minimum temperatures are $22.1^{\circ} \mathrm{C}$ and $6^{\circ} \mathrm{C}$, respectively. The soil type is classified as heavy clay with $\mathrm{pH}$ value of 6 .

\subsection{Experimental Materials}

A total of 49 Kabuli chickpea genotypes listed in Table 1 were used for the study. The seeds were obtained from Debre Zeit Agricultural Research Center (DZARC). The genotypes status was advanced breeding lines developed through hybridization and introduction material by ICARDA.

Table 1. List of experimental materials.

\begin{tabular}{llll}
\hline Genotype code & Genotype Name & Genotype code & Genotype Name \\
\hline G-1 & DZ-2012-CK-0310 & G-26 & DZ-2012-CK-0295 \\
G-2 & DZ-2012-CK-0303 & G-27 & Flip-03-101C \\
G-3 & ICCMABCB-8 & G-28 & ICCV-07313 \\
G-4 & Flip-08-254C & G-29 & ICCV-09315 \\
G-5 & Flip-07-6C & G-30 & DZ-2012-CK-0271 \\
G-6 & Flip-09-155C & G-31 & DZ-2012-CK-0267 \\
G-7 & DZ-2012-CK-0309 & G-32 & DZ-2012-CK-0242 \\
G-8 & Flip-84-92C & G-33 & ICCV-09304 \\
G-9 & Flip-09-188C & G-34 & Flip-09-184C \\
G-10 & ICCMABCB-3 & G-35 & DZ-2012-CK-0062 \\
G-11 & Flip-11-34C & G-36 & DZ-2012-CK-0281 \\
G-12 & DZ-2012-CK-0300 & G-37 & Flip-09-181C \\
G-13 & Flip-93-93C & G-38 & DZ-2012-CK-0286 \\
G-14 & DZ-2012-CK-0269 & G-39 & DZ-2012-CK-0066 \\
G-15 & ICCMABCB-5 & G-40 & DZ-2012-CK-0290 \\
G-16 & ICCMABCC-2 & G-41 & ICCV-10311 \\
G-17 & Flip-03-128C & G-42 & DZ-2012-CK-0274 \\
G-18 & Flip-88-93C & G-43 & Flip-09-377C \\
G-19 & DZ-2012-CK-0276 & G-44 & DZ-2012-CK-0214 \\
G-20 & DZ-2012-CK-0287 & G-45 & Flip-06-14C \\
G-21 & ICCU-09311 & G-46 & DZ-2012-CK-0266 \\
G-22 & ICC-8261 & G-47 & Flip-09-197C \\
G-23 & Flip-05-63C & G-48 & DZ-2012-CK-0305 \\
G-24 & Flip-06-135C & G-49 & Flip-09-120C \\
G-25 & DZ-2012-CK-0294 & & \\
\hline
\end{tabular}

\subsection{Experimental Design and Trial Management}

The experiment was carried out using 7 × 7 simple lattice designs with two replications. The plot size was $4 \mathrm{~m}$ long and $1.2 \mathrm{~m}$ wide, i.e. $4.8 \mathrm{~m}^{2}$ areas with spacing of $0.3 \mathrm{~m}$ and $0.1 \mathrm{~m}$ between rows and plants, respectively as per research recommendation. Each plot had four rows and the spacing between incomplete blocks was $1 \mathrm{~m}$ and $0.6 \mathrm{~m}$ distance were kept between plots to separate two genotypes. The trial was planted at the end of September and planting was done on randomly allocated plots within each replication by hand drilling. $100 \mathrm{kgha}^{-1}$ of NPS fertilizer was applied and all other agronomic practices were done throughout the growing season as per research recommendation.

\subsection{Data Collected}

The data on the following characters were collected on plot basis; days to $50 \%$ flowering (DF), grain filling period (GFP), days to maturity (DM), stand count (SC), hundred seed weight (HSW), grain yield per hectar (GY). 
Data collected from randomly taken five sample plants from two middle rows of each plot; plant height (PLHT), number of primary branches (NPB), number of secondary branches (NSB), number of pods per plant (PPP) and number of seeds per plant (NPPL).

\section{Results and Discussion}

\subsection{Mean Performances of Genotypes}

The result showed significant $(\mathrm{P}<0.05)$ variation for days to $50 \%$ flowering, days to maturity, grain filling period, number of secondary branch, hundred seed weight, number of pods' per plant and grain yield per hectare, number of seed per plant and plant height. These highly significant differences indicate the existence of wide genetic diversity among genotypes. Mean grain yield ranged from $563 \mathrm{Kgha}^{-1}$ to $2,690 \mathrm{Kgha}^{-1}$ with grand mean of $1,315 \mathrm{Kgha}^{-1}$. Maximum mean grain yield was recorded from genotypes G-14 (2,690 $\mathrm{kg} / \mathrm{ha}$ ) followed by genotype G-29, G-12, G-2 and G-6 while lowest grain yield was recorded from genotype G-24 (563 $\mathrm{kg} / \mathrm{h}$ ) (Table 2).

Days to $50 \%$ flowering ranged from 62 to 83 days after sowing with a mean of 68 days. The five genotypes (G-33, G-29, G-14, G-25 and G-26) showed early flowering (62 days after planting), while genotype G-45 showed delayed flowering. Early flowering genotypes have great importance for producing more yields within a year by reducing the days to maturity of the crops. The 49 chickpea genotypes had maturity ranging from 137 to 144 days after sowing. The range of days to maturity between genotypes is not large but eleven genotypes took 137 days after sowing to attain maturity while two genotypes matured late within 144 days after sowing. The mean values of grain filling period for 49 genotypes ranged between 57- 82 days. 19 genotypes took 63 to 70 days for grain filling with non-significant differences, while 28 genotypes took 71 to 77 days of grain filling with non-significant difference (Table 2).

Number of secondary branches showed a wide range of variability ranged from 4 to 13 with a mean of 8 . Maximum number of secondary branches were recorded in genotype G32 followed by G-36 and G-30, while a minimum number was recorded in genotype G-21. Plant height showed a wide range of variability from $43 \mathrm{~cm}$ to $72 \mathrm{~cm}$. The highest plant height was recorded from genotype G-11 and lowest value was recorded from genotype G-44 with a mean of $59 \mathrm{~cm}$ (Table 2).

Number of pods per plant ranged from 26 to 59 with a mean of 44. Number of pods per plant is a significant selection criterion for obtaining high yielder genotypes. The maximum numbers of pods per plant were recorded from genotype G-12 and G-36 followed by genotype G-32 and G2 , while minimum number of pods per plant recorded in genotype G-21. Significant variations $(P<0.05 \%)$ were observed for number of seed per plant. Minimum and maximum numbers of seed per plant were recorded from genotype G-21 and G-2 respectively with a mean of 46 seeds. The nine genotypes have 28 to 33 numbers of seed per plant, while 34 genotypes have ranged from 36 to 59 seeds per plant. Other six genotypes have 63 to 69 numbers of seed per plant. Hundred seed weight ranged from $19.5 \mathrm{~g}$ to $39 \mathrm{~g}$. Maximum hundred seed weight was recorded from genotype G-41 and G-42 with a value of $30 \mathrm{~g}$, while minimum seed weight recorded from genotype G-11 (Table 2).

Table 2. Mean, range and LSD values of 49 kabuli chickpea genotypes.

\begin{tabular}{|c|c|c|c|c|c|c|c|c|c|}
\hline Entry & FD & MD & GFP & SBR & PPP & SPPL & HGT (cm) & HSW (g) & GYH $\left(\mathrm{kgha}^{-1}\right)$ \\
\hline G-1 & $63 a-d$ & $137 \mathrm{a}$ & $73.5 b-d$ & $11.3 \mathrm{~b}-\mathrm{e}$ & $57.0 \mathrm{ab}$ & $65 a$ & $62.5 \mathrm{ab}$ & $26.5 \mathrm{a}-\mathrm{c}$ & $1864.7 \mathrm{c}-\mathrm{f}$ \\
\hline G-2 & $65 a-f$ & $137 \mathrm{ab}$ & $72.1 b-d$ & $10.3 \mathrm{a}-\mathrm{e}$ & $57.5 \mathrm{ab}$ & $69 a$ & $63.7 \mathrm{ab}$ & $25.5 \mathrm{ab}$ & $2363.8 f-i$ \\
\hline G-3 & $65 a-f$ & $138 \mathrm{a}-\mathrm{c}$ & $72.7 b-d$ & $9.9 \mathrm{a}-\mathrm{e}$ & $53.0 \mathrm{ab}$ & $57 \mathrm{a}$ & $54.4 \mathrm{ab}$ & $27.0 \mathrm{a}-\mathrm{d}$ & $1697.3 \mathrm{~b}-\mathrm{h}$ \\
\hline G-4 & $76 b-g$ & $144 \mathrm{e}$ & $68.6 a-c$ & 8.3a-e & $38.5 \mathrm{ab}$ & $33 a$ & $55.2 \mathrm{ab}$ & $29.5 b-e$ & $912.3 \mathrm{a}-\mathrm{d}$ \\
\hline G-5 & $69 a-f$ & $139 a-e$ & $70.0 \mathrm{a}-\mathrm{d}$ & $6.5 a-d$ & $39.0 \mathrm{ab}$ & $57 \mathrm{a}$ & $64.2 \mathrm{ab}$ & $35.5 \mathrm{c}-\mathrm{f}$ & $1160.5 a-e$ \\
\hline G-6 & $63 a-d$ & 140a-e & $77.2 \mathrm{~cd}$ & $8.2 \mathrm{a}-\mathrm{e}$ & $46.0 \mathrm{ab}$ & $33 a$ & $65.7 \mathrm{ab}$ & $31.5 b-f$ & $2114.3 \mathrm{e}-\mathrm{i}$ \\
\hline G-7 & $63 a-d$ & 139a-e & $75.4 b-d$ & 7.4a-e & $49.5 \mathrm{ab}$ & $48 \mathrm{a}$ & $67.0 \mathrm{ab}$ & $34.5 b-f$ & $1289.6 \mathrm{a}-\mathrm{g}$ \\
\hline G-9 & $70 \mathrm{a}-\mathrm{g}$ & 140a-e & $70.3 \mathrm{a}-\mathrm{d}$ & 10.1a-e & $54.5 \mathrm{ab}$ & $49 a$ & $64.7 \mathrm{ab}$ & $31.5 b-f$ & $869.5 a-d$ \\
\hline G-10 & $65 a-f$ & $138 a-d$ & $73.5 b-d$ & $6.7 a-d$ & $49.0 \mathrm{ab}$ & $47 a$ & $47.6 \mathrm{ab}$ & $28.0 \mathrm{a}-\mathrm{d}$ & $1528.2 \mathrm{a}-\mathrm{h}$ \\
\hline G-11 & $72 a-g$ & 139a-e & $67.6 a-c$ & $6.2 \mathrm{a}-\mathrm{d}$ & $49.0 \mathrm{ab}$ & $50 \mathrm{a}$ & $71.6 \mathrm{~b}$ & $19.5 \mathrm{a}$ & 1366.7a-h \\
\hline G-12 & $63 a-d$ & $138 \mathrm{a}-\mathrm{c}$ & $74.9 b-d$ & $8.3 \mathrm{a}-\mathrm{e}$ & $59.0 \mathrm{~b}$ & $63 a$ & $54.4 \mathrm{ab}$ & $30.5 b-f$ & $2395.7 \mathrm{~g}-\mathrm{i}$ \\
\hline G-13 & $67 a-f$ & $139 a-e$ & $72.2 b-d$ & $8.4 \mathrm{a}-\mathrm{e}$ & $49.5 \mathrm{ab}$ & $49 a$ & $59.4 \mathrm{ab}$ & $26.0 \mathrm{ab}$ & 781.1a-d \\
\hline G-14 & $62 a-c$ & $144 \mathrm{e}$ & $81.8 \mathrm{~d}$ & 9.1a-e & $57.0 \mathrm{ab}$ & $65 a$ & $65.7 \mathrm{ab}$ & $26.0 \mathrm{ab}$ & $2690.0 \mathrm{i}$ \\
\hline G-15 & $63 a-d$ & $137 \mathrm{ab}$ & $73.5 b-d$ & $9.7 \mathrm{a}-\mathrm{e}$ & $45.0 \mathrm{ab}$ & $47 a$ & $52.7 \mathrm{ab}$ & $26.0 \mathrm{ab}$ & $1810.8 \mathrm{c}-\mathrm{f}$ \\
\hline G-16 & 64a-e & $137 \mathrm{ab}$ & $72.5 b-d$ & 5.7a-d & $43.0 \mathrm{ab}$ & $45 a$ & $57.2 \mathrm{ab}$ & $30.5 b-f$ & $1404.3 \mathrm{a}-\mathrm{h}$ \\
\hline G-18 & $76 b-g$ & $144 c-e$ & $68.2 \mathrm{a}-\mathrm{c}$ & 8.6a-e & $53.5 \mathrm{ab}$ & $56 a$ & $64.0 \mathrm{ab}$ & $26.5 \mathrm{a}-\mathrm{c}$ & $1185.3 a-f$ \\
\hline G-19 & $78 \mathrm{fg}$ & $142 \mathrm{~b}-\mathrm{e}$ & $64.5 \mathrm{a}-\mathrm{c}$ & 8.3a-e & $31.5 \mathrm{ab}$ & $33 a$ & $55.9 \mathrm{ab}$ & $27.5 \mathrm{a}-\mathrm{d}$ & $619.0 \mathrm{ab}$ \\
\hline G-20 & $65 a-f$ & $140 a-e$ & $74.5 b-d$ & 8.3a-e & $31.0 \mathrm{ab}$ & $31 \mathrm{a}$ & $65.9 \mathrm{ab}$ & $34.5 b-f$ & 979.5a-e \\
\hline G-21 & $65 a-f$ & $138 \mathrm{a}-\mathrm{d}$ & $73.0 \mathrm{~b}-\mathrm{d}$ & $3.7 \mathrm{a}$ & $26.0 \mathrm{a}$ & $28 \mathrm{a}$ & $54.7 \mathrm{ab}$ & $33.5 b-f$ & $1143.8 \mathrm{a}-\mathrm{e}$ \\
\hline G-22 & $64 a-d$ & $137 \mathrm{ab}$ & $74.3 \mathrm{~b}-\mathrm{d}$ & $6.4 a-d$ & $46.0 \mathrm{ab}$ & $46 a$ & $54.5 \mathrm{ab}$ & $28.0 \mathrm{a}-\mathrm{d}$ & $1538.5 \mathrm{a}-\mathrm{i}$ \\
\hline G-23 & $70 a-g$ & $140 a-e$ & $70.0 \mathrm{a}-\mathrm{d}$ & $5.6 a-d$ & $38.5 \mathrm{ab}$ & $48 \mathrm{a}$ & $63.2 \mathrm{ab}$ & $33.5 b-f$ & $694.9 \mathrm{a}-\mathrm{c}$ \\
\hline G-24 & 71a-g & 141a-e & $70.8 \mathrm{~b}-\mathrm{d}$ & 7.1a-e & $36.0 \mathrm{ab}$ & $40 \mathrm{a}$ & $57.7 \mathrm{ab}$ & $32.0 \mathrm{~b}-\mathrm{f}$ & $563.0 \mathrm{a}$ \\
\hline G-25 & $62 a-c$ & $138 \mathrm{a}-\mathrm{c}$ & $75.8 \mathrm{~b}-\mathrm{d}$ & $8.6 a-e$ & $55.5 \mathrm{ab}$ & $65 a$ & $66.7 \mathrm{ab}$ & $29.5 b-e$ & $1884.0 \mathrm{~d}-\mathrm{i}$ \\
\hline
\end{tabular}




\begin{tabular}{|c|c|c|c|c|c|c|c|c|c|}
\hline Entry & FD & MD & GFP & SBR & PPP & SPPL & HGT (cm) & HSW (g) & GYH $\left(\mathrm{kgha}^{-1}\right)$ \\
\hline G-26 & $62 a-c$ & $137 \mathrm{a}$ & $74.6 \mathrm{~b}-\mathrm{d}$ & 7.7a-e & $38.0 \mathrm{ab}$ & $36 a$ & $56.9 \mathrm{ab}$ & $29.0 \mathrm{~b}-\mathrm{d}$ & $1768.3 \mathrm{c}-\mathrm{f}$ \\
\hline G-27 & $69 a-f$ & $139 a-e$ & $70.6 b-d$ & $8.2 \mathrm{a}-\mathrm{e}$ & $41.5 \mathrm{ab}$ & $41 \mathrm{a}$ & $61.9 \mathrm{ab}$ & $30.0 \mathrm{~b}-\mathrm{f}$ & $1404.8 \mathrm{a}-\mathrm{h}$ \\
\hline G-28 & 69a-f & $138 a-d$ & 69.0a-d & $10.8 \mathrm{~b}-\mathrm{e}$ & $56.5 \mathrm{ab}$ & $67 a$ & $58.1 \mathrm{ab}$ & $36.0 \mathrm{~d}-\mathrm{f}$ & $1803.8 \mathrm{c}-\mathrm{f}$ \\
\hline G-29 & $62 \mathrm{ab}$ & $138 a-e$ & $76.1 \mathrm{~b}-\mathrm{d}$ & $8.7 \mathrm{a}-\mathrm{e}$ & $52.5 \mathrm{ab}$ & $59 a$ & $67.7 \mathrm{ab}$ & $29.0 \mathrm{~b}-\mathrm{d}$ & 2499.7hi \\
\hline G-30 & $69 a-f$ & $142 a-e$ & $72.1 \mathrm{~b}-\mathrm{d}$ & $11.7 \mathrm{c}-\mathrm{e}$ & $54.0 \mathrm{ab}$ & $48 \mathrm{a}$ & $59.2 \mathrm{ab}$ & $31.0 \mathrm{~b}-\mathrm{f}$ & $716.2 \mathrm{a}-\mathrm{d}$ \\
\hline G-31 & $75 c-g$ & $141 a-e$ & $65.3 a-c$ & $6.3 \mathrm{a}-\mathrm{d}$ & $35.0 \mathrm{ab}$ & $39 a$ & $64.7 \mathrm{ab}$ & $33.0 \mathrm{~b}-\mathrm{f}$ & $754.4 a-d$ \\
\hline G-32 & $71 \mathrm{a}-\mathrm{g}$ & $143 \mathrm{~b}-\mathrm{e}$ & $71.6 \mathrm{~b}-\mathrm{d}$ & $13.5 \mathrm{~d}$ & $59.0 \mathrm{~b}$ & $58 \mathrm{a}$ & $55.9 \mathrm{ab}$ & $29.0 \mathrm{~b}-\mathrm{d}$ & 1013.3a-e \\
\hline G-33 & $62 \mathrm{a}$ & $137 \mathrm{ab}$ & $75.2 b-d$ & $5.4 \mathrm{a}-\mathrm{d}$ & $47.5 \mathrm{ab}$ & $44 a$ & $55.9 \mathrm{ab}$ & $32.5 b-f$ & 1730.4a-i \\
\hline G-34 & $75 c-g$ & $140 a-e$ & $64.6 \mathrm{a}-\mathrm{c}$ & $8.0 \mathrm{a}-\mathrm{e}$ & $32.0 \mathrm{ab}$ & $31 \mathrm{a}$ & $53.9 \mathrm{ab}$ & $33.5 b-f$ & 761.3a-d \\
\hline G-35 & $66 a-f$ & $138 \mathrm{a}-\mathrm{e}$ & $71.6 b-d$ & $5.0 \mathrm{ab}$ & $30.0 \mathrm{ab}$ & $43 a$ & $56.4 \mathrm{ab}$ & $27.5 \mathrm{a}-\mathrm{d}$ & $1265.8 \mathrm{a}-\mathrm{g}$ \\
\hline G-36 & $63 a-c$ & $138 a-d$ & $74.8 \mathrm{~b}-\mathrm{d}$ & $12.0 \mathrm{de}$ & $58.0 \mathrm{ab}$ & $52 \mathrm{a}$ & $62.0 \mathrm{ab}$ & $27.0 \mathrm{a}-\mathrm{d}$ & $953.4 \mathrm{a}-\mathrm{e}$ \\
\hline G-37 & 71a-g & $138 \mathrm{a}-\mathrm{e}$ & $67.1 \mathrm{a}-\mathrm{c}$ & $8.2 \mathrm{a}-\mathrm{e}$ & $30.0 \mathrm{ab}$ & $41 \mathrm{a}$ & $63.8 \mathrm{ab}$ & $30.5 b-f$ & $1344.7 \mathrm{a}-\mathrm{g}$ \\
\hline G-38 & $69 a-f$ & $139 a-e$ & $70.2 a-d$ & $9.8 \mathrm{a}-\mathrm{e}$ & $57.0 \mathrm{ab}$ & $47 a$ & $60.7 \mathrm{ab}$ & $26.0 \mathrm{ab}$ & $1301.4 \mathrm{a}-\mathrm{g}$ \\
\hline G-39 & 73a-g & $142 a-e$ & $69.2 \mathrm{a}-\mathrm{d}$ & $9.8 \mathrm{a}-\mathrm{e}$ & $45.0 \mathrm{ab}$ & $36 a$ & $55.7 \mathrm{ab}$ & $29.0 \mathrm{~b}-\mathrm{d}$ & 892.9a-d \\
\hline G-40 & $64 a-d$ & $139 a-e$ & $75.3 b-d$ & $11.3 \mathrm{~b}-\mathrm{e}$ & $52.0 \mathrm{ab}$ & $58 \mathrm{a}$ & $61.7 \mathrm{ab}$ & $28.5 \mathrm{a}-\mathrm{d}$ & $1566.9 \mathrm{a}-\mathrm{i}$ \\
\hline G-41 & $66 a-f$ & $138 \mathrm{a}-\mathrm{e}$ & $72.1 \mathrm{~b}-\mathrm{d}$ & $5.4 \mathrm{a}-\mathrm{c}$ & $37.5 \mathrm{ab}$ & $39 a$ & $53.5 \mathrm{ab}$ & $38.5 \mathrm{ef}$ & 1336.9a-h \\
\hline G-42 & 71a-g & $140 a-e$ & 69.1a-d & $6.6 a-d$ & $35.0 \mathrm{ab}$ & $37 a$ & $63.2 \mathrm{ab}$ & $39.0 \mathrm{f}$ & 1144.1a-e \\
\hline G-43 & $64 a-f$ & $139 a-e$ & $74.5 b-d$ & $8.3 \mathrm{a}-\mathrm{e}$ & $38.0 \mathrm{ab}$ & $37 a$ & $54.5 \mathrm{ab}$ & $30.5 b-f$ & $952.5 \mathrm{a}-\mathrm{d}$ \\
\hline G-44 & $76 \mathrm{~d}-\mathrm{g}$ & 140a-e & $64.1 \mathrm{a}-\mathrm{c}$ & $8.5 \mathrm{a}-\mathrm{e}$ & $31.5 \mathrm{ab}$ & $32 \mathrm{a}$ & $43.2 \mathrm{a}$ & $32.5 b-f$ & 796.5a-d \\
\hline G-45 & $83 \mathrm{~g}$ & $140 a-e$ & $56.9 \mathrm{a}$ & 7.1a-e & $29.0 \mathrm{ab}$ & $40 \mathrm{a}$ & $60.5 \mathrm{ab}$ & $32.5 b-f$ & $622.3 \mathrm{ab}$ \\
\hline G-46 & $69 a-f$ & $141 a-e$ & $71.8 b-d$ & 7.0a-e & $32.0 \mathrm{ab}$ & $49 a$ & $52.3 \mathrm{ab}$ & $32.5 b-f$ & $942.4 a-d$ \\
\hline G-47 & 73a-g & $141 \mathrm{a}-\mathrm{e}$ & $68.1 \mathrm{a}-\mathrm{c}$ & $7.5 \mathrm{a}-\mathrm{e}$ & $44.5 \mathrm{ab}$ & $31 \mathrm{a}$ & $59.2 \mathrm{ab}$ & $31.0 \mathrm{~b}-\mathrm{f}$ & $1246.0 \mathrm{a}-\mathrm{g}$ \\
\hline G-48 & 63a-d & $139 a-e$ & $75.4 \mathrm{~b}-\mathrm{d}$ & $8.7 a-e$ & $52.5 \mathrm{ab}$ & $46 a$ & $65.6 \mathrm{ab}$ & $29.0 \mathrm{~b}-\mathrm{d}$ & $1486.8 \mathrm{a}-\mathrm{h}$ \\
\hline G-49 & $77 \mathrm{e}-\mathrm{g}$ & $140 a-e$ & $63.1 \mathrm{ab}$ & $8.3 \mathrm{a}-\mathrm{e}$ & $42.0 \mathrm{ab}$ & $56 \mathrm{a}$ & $64.5 \mathrm{ab}$ & $30.5 b-f$ & 1405.0a-h \\
\hline Mean & 68 & 139 & 71 & 8 & 44 & 46 & 59 & 30 & 1315 \\
\hline Range & $62-83$ & $137-144$ & $57-82$ & $4-13$ & $26-59$ & $28-69$ & $43-72$ & $20-39$ & $569-2690$ \\
\hline SE & 2.5 & 1.0 & 2.4 & 1.2 & 5.9 & 7.9 & 4.6 & 1.7 & 218.0 \\
\hline LSD & 6.4 & 2.9 & 6.3 & 3.1 & 16.5 & 22.4 & 12.7 & 4.8 & 532.8 \\
\hline
\end{tabular}

$\mathrm{MD}=$ days to maturity, $\mathrm{FD}=$ days to $50 \%$ flowering, $\mathrm{GFP}=$ grain filling period, $\mathrm{SBR}=$ secondary branches, $\mathrm{PPP}=$ number of pods per plant, $\mathrm{SPPL}=$ number of seeds per plant, $\mathrm{HGT}=$ plant height in $\mathrm{cm}, \mathrm{HSW}=$ hundred seed weight in $\mathrm{g}, \mathrm{GYH}\left(\mathrm{kgha}^{-1}\right)=$ grain yield in $\mathrm{kg} / \mathrm{ha}$.

\subsection{Genetic Divergence Analysis}

\subsubsection{Cluster Analysis}

The distribution of 49 kabuli chickpea genotypes classified into six clusters. Cluster-IV consisted of maximum number of genotypes and has 14 genotypes that are $28.57 \%$ of the total genotypes evaluated. The genotypes in this cluster indicate had narrow genetic diversity among them. The higher number genotypes next to these cluster was cluster-V, cluster II and cluster-III which consist of eleven, ten and nine genotypes respectively. Cluster-I and cluster VI consists of a minimum number of genotypes have accounts five genotypes (10.2\%). The 155 Ethiopian chickpea collection materials which are done on the study of genetic diversity and population structure, they are grouped in to five distinct clusters [16].

Sharifi, Astereki and Pouresmael [8] classified 25 genotypes into four clusters. [9] classified 22 chickpea genotypes into five clusters and observed the presense of high genetic distance among genotypes. [10] studied the genetic diversity of 49 kabuli chickpea genotypes and grouped into eight clusters. The largest numbers of genotypes are in cluster I and II which consists of ten genotypes. Distances between these clusters showed significantly different for all the cluster except cluster I and IV. [11] classified 60 chickpea genotypes into five clusters and the maximum inter-cluster distance was found between cluster-III and IV followed by cluster-IV and V and cluster-II and IV; indicating that genotypes included in these clusters are genetically diverse.

Table 3. Clusters of 49 kabuli chickpea genotypes.

\begin{tabular}{llll}
\hline Cluster & No of genotype & Percent (\%) & Genotype code \\
\hline Cluster-I & 4 & 8.16 & G-4, G-6, G-12, G-22 \\
Cluster-II & 10 & 20.41 & G-9, G-13, G-26, G-30, G-33, G-34, G-38, G-41, G-48, G-49 \\
Cluster-III & 9 & 18.37 & G-5, G-11, G-16, G-17, G-24, G-25, G-28, G-39, G-40 \\
Cluster-IV & 14 & 28.57 & G-3, G-8, G-10, G-14, G-20, G-29, G-31, G-32, G-36, G-37, G-42, G-44, G-45, G-47 \\
Cluster-V & 11 & 22.45 & G-1, G-2, G-7, G-15, G-18, G-19, G-21, G-23, G-27, G-35, G-43 \\
Cluster-VI & 1 & 2.04 & G-46 \\
\hline
\end{tabular}

$\mathrm{G}=$ genotypes.

\subsubsection{Distance Analysis}

The intra and inter cluster distance showed the presence of significant genotypic difference among the clusters and within clusters except with in cluster VI as tested by chi- square distribution. The intra cluster distances ranged from 0.00 to 514 (Table 4 ). The maximum intra cluster distance was found in cluster-I $\left(D^{2}=514\right)$ followed by cluster-IV $\left(D^{2}\right.$ $=470)$, cluster-V $\left(\mathrm{D}^{2}=389\right)$ and cluster-II and cluster-III $\left(\mathrm{D}^{2}\right.$ $=347)$. The higher intra cluster distance of cluster-I $\left(\mathrm{D}^{2}=\right.$ 
514) indicates the genotypes included in this cluster were more divergent than other clusters. The highly significant ( $P$ $<0.01$ ) and maximum inter cluster distances (Table 4) were recorded between cluster-III and cluster-IV $\left(D^{2}=2,127\right)$ followed by cluster-IV and cluster-V $\left(\mathrm{D}^{2}=2,073\right)$, between cluster-II and cluster-IV $\left(D^{2}=1,974\right)$ and between cluster-I and cluster-III $\left(D^{2}=1,831\right)$ this indicates that the presence of maximum genetic distance among genotypes between those clusters. Thus crossing and selection of genotypes from these clusters can produce efficient genotypes or offspring that lead to the development of better performing varieties than the released varieties.

The minimum inter cluster distance was found between cluster-II and cluster-VI $\left(\mathrm{D}^{2}=827\right)$ followed by cluster-III and cluster-VI, between cluster-V and cluster-VI $\left(\mathrm{D}^{2}=\right.$ $1,420)$ and between cluster-I and cluster-VI $\left(D^{2}=1,453\right)$, this indicates that these clusters are relatively divergent from each other and the genotypes belonging to them can be used for hybridization program. [10] studied the genetic diversity of 49 kabuli chickpea genotypes and distances between these clusters showed significantly different for all cluster except cluster I and IV. Maximum inter-cluster distance between cluster-III and IV followed by cluster-IV and V and cluster-II and IV [11], indicating that genotypes included in these clusters are more genetically different. Crossing genotypes that are distant clusters for wide genetic distance (D2) could maximize transgressive segregation [12].

Table 4. Intra (bold) and inter-cluster distances $\left(D^{2}\right)$ values in 49 chickpea genotypes.

\begin{tabular}{llllll}
\hline Clusters & Cluster-I & Cluster-II & Cluster-III & Cluster-IV & \\
\hline Cluster-I & 514 & & & & \\
Cluster-II & $1678^{* *}$ & 347 & 347 & & \\
Cluster-III & $1831^{* *}$ & $1205^{* *}$ & $2127 * *$ & 470 & \\
Cluster-IV & $1781^{* *}$ & $1974 * *$ & $1799 * *$ & $2073 * *$ & 389 \\
Cluster-V & $1776^{* *}$ & $1646^{* *}$ & $943 * *$ & $1749 *$ & $1420 * *$ \\
Cluster-VI & $1453^{* *}$ & $827 * *$ & 0 & \\
\hline
\end{tabular}

$* *=$ Significant at $1 \%$ of level of significance.

Table 5. Mean values of 9 traits of six clusters of 49 kabuli chickpea genotypes.

\begin{tabular}{|c|c|c|c|c|c|c|c|c|c|}
\hline Traits & FD & MD & GFP & SBR & PPP & SPPL & HGT (cm) & HSW (g) & GYH $\left(\mathrm{kgha}^{-1}\right)$ \\
\hline Cluster-I & 66 & 140 & 74 & 8 & 47 & 44 & 57 & 30 & 1,740 \\
\hline Cluster-II & 68 & 139 & 71 & 8 & 46 & 45 & 59 & 31 & 1,216 \\
\hline Cluster-III & 68 & 139 & 71 & 8 & 45 & 50 & 61 & 31 & 1,294 \\
\hline Cluster-IV & 69 & 140 & 70 & 9 & 42 & 45 & 59 & 31 & 1,295 \\
\hline Cluster-V & 67 & 139 & 71 & 8 & 43 & 47 & 60 & 29 & 1,326 \\
\hline Cluster-VI & 69 & 141 & 72 & 7 & 32 & 49 & 52 & 33 & 942 \\
\hline
\end{tabular}

$\mathrm{MD}=$ days to maturity, $\mathrm{FD}=$ days to $50 \%$ flowering, $\mathrm{GFP}=$ grain filling period, $\mathrm{SBR}=$ secondary branches, $\mathrm{PPP}=$ number of pods per plant, $\mathrm{SPPL}=$ number of seeds per plant, $\mathrm{HGT}=$ plant height $\mathrm{HSW}=$ hundred seed weight, $\mathrm{GYH}\left(\mathrm{kgha}^{-1}\right)=$ grain yield.

\subsection{Mean Values of the Clusters}

Cluster-I consisted of four genotypes and the mean performances were characterized by the highest cluster mean values for grain filling period, number of pods per plant, root rot and grain yield per hectare. But it also characterized by the lowest cluster mean value for number of seed per plant, number of seed per pod and days to $50 \%$ flowering. Cluster II consisted of 10 genotypes and characterized by the second lowest cluster mean value in number of seed per plant, number of secondary branches and grain filling period. Cluster-III also consisted of 9 genotypes characterized by the highest cluster mean value for number of seed per plant and plant height.

The fourth cluster (IV) was characterized by the highest cluster mean value in number of secondary branches and days to $50 \%$ flowering. Cluster $\mathrm{V}$ consisted of 11 genotypes and characterized by the second highest cluster mean values for number of secondary branches, plant height and grain yield per hectare. Cluster VI consisted of only one genotypes characterized by the highest cluster mean value for days to
$50 \%$ flowering, days to maturity, hundred seed weight, but it also characterized by the lowest mean cluster value for number of secondary branches, plant height and grain yield per hectare.

\subsection{Principal Component Analysis}

The principal component analysis showed that the first three principal components have Eigenvalues greater than 1 explained about $66.1 \%$ of the total variation among fortynine kabuli chickpea genotypes evaluated for eleven quantitative traits. The three principal components had eigenvalues $3.8047,2.1342$ and 1.3332 respectively.

The first principal component accounts $34.58 \%$ of the total variation of genotypes. Days to $50 \%$ flowering, grain filling period, number of seed per plant, number of pods per plant and grain yield had high contributions for the variation in first principal components; those imply that they contribute significantly to the discrimination among the genotypes. The second principal component accounted about $19.40 \%$ of the total variation of the genotypes. Number of secondary branch, days to maturity, days to $50 \%$ flowering, root rot and 
numbers of pods per plant had high contributions for the total variation. The third principal component analysis accounted about $12.12 \%$ of total variation by number of seed per plant, root rot, hundred seed weight and grain filling period.

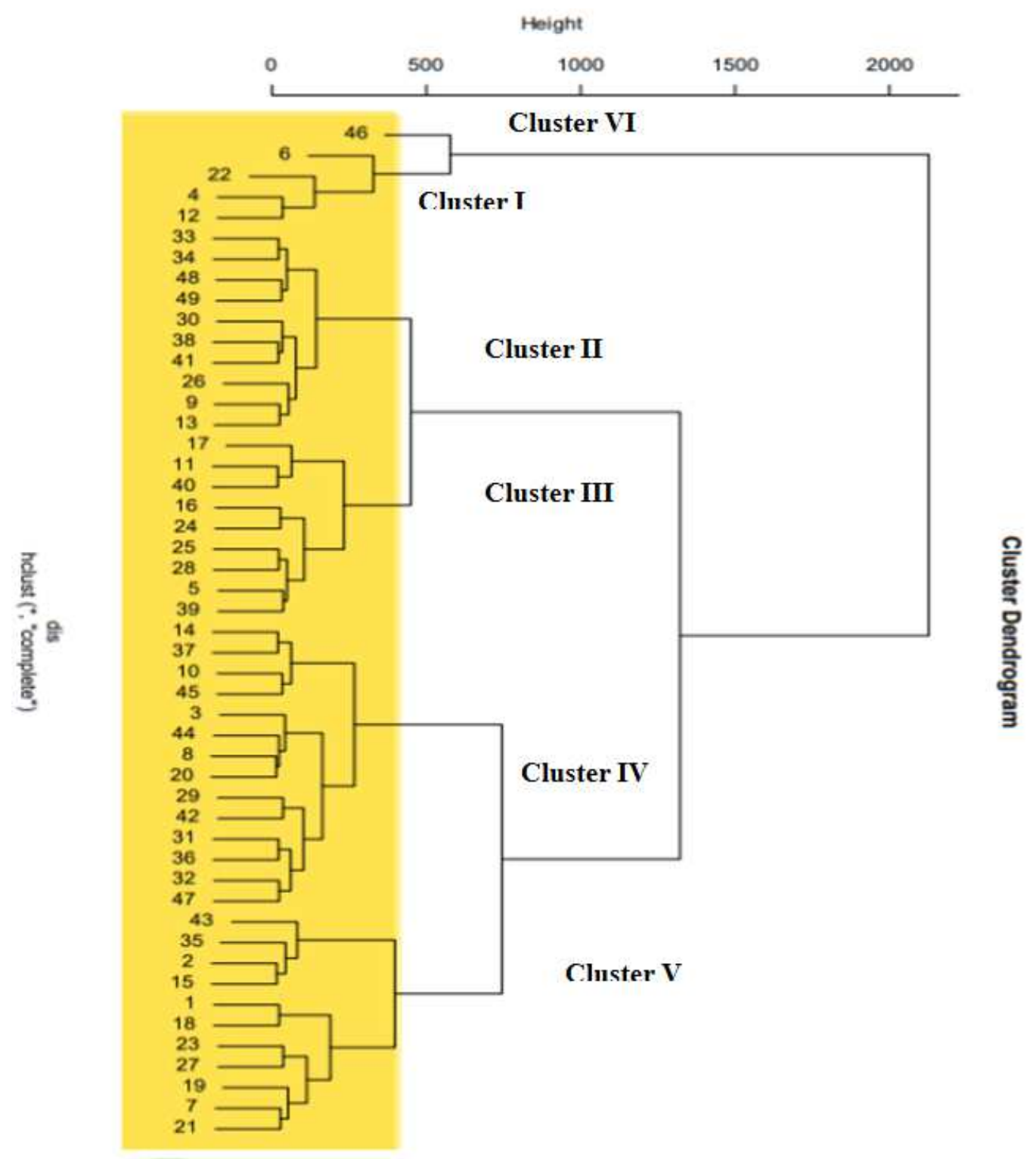

Figure 1. The dendrogram showing 49 chickpea genotypes clustering based on complete linkage.

Similar finding were reported by [8] in which $69.69 \%$ of variation were explained by the first three principal components. [10] eveluated 49 kabuli chickpea genotypes and reported that about $79.92 \%$ of the total variation were explained by the first four principal components. According to his study characters having higher contribution in the first principal components are days to $50 \%$ flowering, days to maturity, number of primary branch, number of secondary branch and number of seeds' per pod. Number of pods per plant, number of seeds per pod, number of branches per plant and 100 seed weight contributed greater variation to the total variance of the first two principal component axes [13].

Tesfamichael et al. studied 37 genotypes and reported $80.14 \%$ of the total variation explained by the first three principal components [14]. In his study about $56.96 \%$ of the variations were explained by the first principal components.
Days to $50 \%$ flowering, days to maturity, number of secondary branch, number of primary branch, number of pods per plant and hundred seed weight were contributed more for the variation. [8] studied 25 chickpea genotypes and reported that $69.69 \%$ of the total variation were explained by the first three principal components. The first two principal componets explained about $93.7 \%$ of total variation and suggesting high genetic variability among the genotypes [15]. The first four principal components in the study of qualitative traits of desi and kbuli chickpea genotypes about $81.71 \%$ of the total variation in the genotypes were explained by these four components [17].

The first two principal components plot using variables revealed that days to $50 \%$ flowering, number of secondary branches, number of pods' per plant and grain yield loaded more contribution for the total variation (Figure 2). 


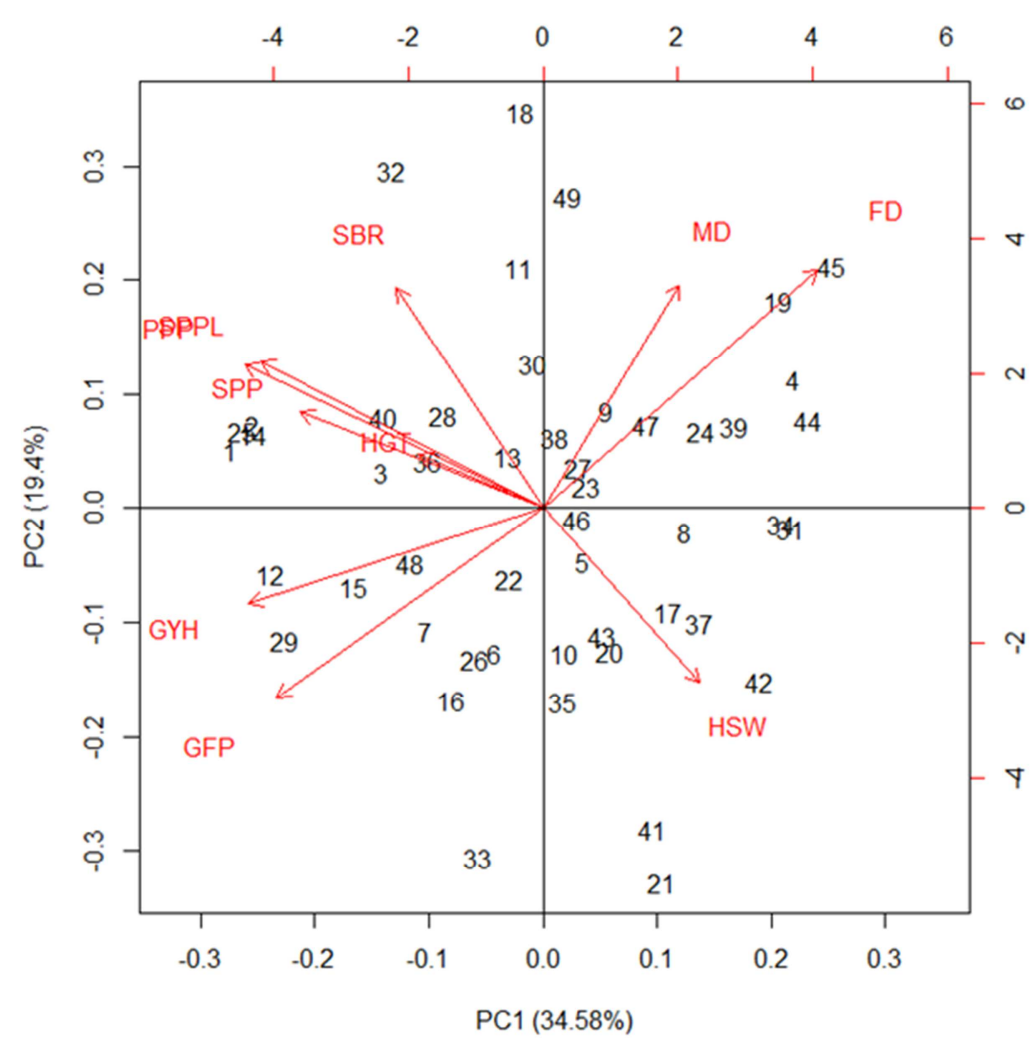

Figure 2. Plots of the first two principal components of 9 traits for 49 kabuli chickpea genotypes.

Table 6. First three principal components of 9 traits of kabuli chickpea genotypes.

\begin{tabular}{llll}
\hline Traits & Component-1 & Component-2 & Component-3 \\
\hline FD & 0.424 & 0.335 & 0.296 \\
MD & 0.220 & 0.369 & 0.097 \\
GFP & -0.408 & -0.243 & -0.307 \\
SBR & -0.190 & 0.495 & -0.251 \\
PPP & -0.420 & 0.347 & -0.001 \\
SPPL & -0.359 & 0.225 & 0.339 \\
HGT (cm) & -0.181 & 0.103 & 0.328 \\
HSW (g) & 0.204 & -0.324 & -0.235 \\
GYH (kgha $\left.{ }^{-1}\right)$ & -0.433 & -0.159 & 0.152 \\
Eigenvalues & 3.8047 & 2.1342 & 1.3332 \\
Proportion $(\%)$ & 0.3459 & 0.194 & 0.1212 \\
Cumulative & 0.3458 & 0.5398 & 0.661 \\
\hline
\end{tabular}

$\mathrm{MD}=$ days to maturity, $\mathrm{FD}=$ days to $50 \%$ flowering, $\mathrm{GFP}=$ Grain filling period, SBR $=$ Number of Secondary branches, $\mathrm{PPP}=$ Number of Pods per plant, $\mathrm{SPPL}=$ Number of seeds per plant, $\mathrm{HGT}=$ plant height in $\mathrm{cm}, \mathrm{HSW}=$ Hundred seed weight in $\mathrm{g}$, GYH $\left(\mathrm{kgha}^{-1}\right)=$ grain yield per hectar.

\section{Conclusion}

The kabuli chickpea genotypes grouped into six clusters. Intra and inter cluster distance showed the presence of highly significant genetic diversity among genotypes with the cluster. The maximum intra cluster distance was found in cluster-I $\left(D^{2}=514\right)$ followed by cluster-IV $\left(D^{2}=470\right)$ and cluster-V $\left(\mathrm{D}^{2}=389\right)$. The maximum inter cluster distance was recorded between cluster-III and cluster-IV $\left(D^{2}=2,127\right)$ followed by cluster-IV and cluster-V $\left(D^{2}=2,073\right)$. The principal component analysis showed about $66.1 \%$ of the total variation was explained by the first three principal components. The first principal components accounted about $34.58 \%$ of the total variation and mainly contributed by days to $50 \%$ flowering, grain filling period, grain yield, number of pods' per plant and seed per plant. The second principal component analysis accounted about $19.4 \%$ of the total variation, mainly contribution from number of secondary branch, days to maturity, days to $50 \%$ flowering and numbers of pods per plant.

The breeders can select the crossing materials from divergent or distant clusters. Distant inter clusters, cluster-IV and cluster-III, cluster-IV and cluster-V, and cluster-II and cluster-IV will be used as parent materials for crossing. In order to develop higher yielder varieties, available genetic resources should be exploited in the breeding program. In this study the amounts of genetic variability were determined among grain yield and yield related traits. However, it requires multi location and year trials to verify the consistency of existing genotypic variability.

\section{References}

[1] Muehlbauer, F. J. and Sarker, A., 2017. Economic importance of chickpea: production, value, and world trade. In The Chickpea Genome (pp. 5-12). Springer, Cham.

[2] Van der Maesen, L. J. G. 1987. Origin, History and Taxonomy of Chickpea. In: The Chickpea, pp11, (M. C. Saxena and K. B. Singh, eds.), CAB International, Wallingford, The international Center for Agricultural Research in the Dry Areas. 
[3] Gaur, M. P., Aravind, K. J. and Rajeev, K. V. 2012. A review of impact of Genomic technologies on chickpea breeding strategies. Agronomy, 2: 200-203, India.

[4] CSA (Central Statistical Authority). 2018. Agricultural sample survey, Report on, area and production for major crops (private peasant holdings, meher season). Addis Ababa, Ethiopia.

[5] ICRISAT (International Crops Research Institute for the SemiArid Tropics). 2015. Ethiopia and ICRISAT working with partners for prosperous semi-arid tropics, crops: chickpea.

[6] Wood, J. A. and Grusak, M. A. 2007. Nutritional value of chickpea. pp. 101-142. In: S. S. Yadav, R. Redden, W. Chen and B. Sharma (eds.). Chickpea Breeding and Management. $C A B$, Wallingford, UK.

[7] Upadhyaya, H. D., Ortiz, R., Bramel, P. J. and Singh, S., 2002. Phenotypic diversity for morphological and agronomic traits in chickpea core collection. Euphytica. 123: 333 - 342.

[8] Sharifi, P., Astereki, H., and Pouresmael, M. 2018. Evaluation of variations in chickpea (Cicer arietinum $\mathrm{L}$.) yield and yield components by multivariate technique. Annals of Agrarian Science, 16, 136-142.

[9] Pandey, A., Kumar, A., Thongbam, P., and Pattanayak, A. 2013. Genetic divergence, path coefficient and cluster analysis of chickpea (Cicer arietinum L.) cultivars, in the mid-altitudes of Meghalaya. Indian Journal of Agricultural Sciences. December 2013. 1300-1304.

[10] Temesgen Alene, Mandefro Nigussie and Habtamu Zeleke. 2015. Genetic divergence study among Kabuli chickpea (Cicer arietinum L.) genotypes. Scholarly Journal of Agricultural Science, 5 (5): 183-188.
[11] Mayuriben, R., Sunayan, R., Sunil, S., Arpan, J., and Harshad, N. 2019. Diversity study through D2 analysis in Chickpea. The Pharma Innovation Journal; 8 (9): 140-143.

[12] Amsalu Ayana and Endashew Bekele. 1999. Multivariate analysis of morphological variation in sorghum (Sorghum bicolor (L) Moench) germplasm from Eritrea and Ethiopia. Genetic Resources and Crop Evolution 46 (3): 273-284.

[13] Arora, R. N. 2018. Principal component analysis in kabuli chickpea (Cicer arietinum L.). International Journals of Crop Science, 6 (2): 2767-2768.

[14] Tesfamichael, S. M., Githiri, S. M., Nyende, A. B. and Rao, N. V. P. R. G., 2015. Variation for agro morphological traits among kabuli chickpea (Cicer arietinum L.) genotypes. Journal of Agricultural Science, 7 (7): 75.

[15] Dagnachew Bekele, Kassahun Tesfaye and Asnake Fikrie (2020). Genetic diversity analysis of advanced chickpea (Cicer arietinum L.) genotypes in Ethiopia for identification of high-yielding and novel Fusarium wilt resistance sources. Journal of Crop Science and Biotechnology Volume 24, pages 191-201.

[16] Gemechi Keneni, Endashaw Bekele, Muhammad Imtiaz, Kifle Dagne, Emana Getu and Fasil Assefa (2011). Genetic Diversity nd population structure of Ethiopian Chickpea (Cicer arietinum L.) Germplasm Accessions from Different Geographical Origins as Revealed by Microsatellite Markers. Plant Mol Biol Rep DOI 10.1007/s11105-0110374-6.

[17] Asha Ahmed (2020). Genetic Diversity study of Kabuli and Desi type Chickpea (Cicer arietinum L.) varieties using Agromorphologicl traits, Nutritional Composition and ISSR Marker. Addis Ababa University. 